\title{
Território: conceito estratégico na assistência social
}

\author{
Territory: strategic concept in social work
}

\author{
Paula Fonseca do Nascimento* \\ Everaldo Santos Melazzo**
}

\begin{abstract}
Resumo:
Este artigo aborda a dimensão territorial na perspectiva da Política Pública de Assistência Social. Constrói-se, aqui, a ideia deste conceito como estratégico para a organização da Política de Assistência Social, perspectiva esta que exige novos olhares para a compreenssão dos processos que levam diferentes grupos sociais a situações de vulnerabilidade e risco social. O conceito de território ultrapassa os limites da Geografia, mas nela deve se apoiar para contruir uma perspectiva analítica e de intervenção que o tome como um campo de forças e relações sociais que se organizam em um espaço de vida com dinâmicos movimentos, em múltiplas escalas. 0 reconhecimento do território pode, ainda, ser tomado como estratégico para o estabelecimento de diferentes prioridades no campo das políticas públicas, indo além de ações de localização de equipamentos públicos como os CRAS. Neste trabalho, destaca-se o território usado a partir da perspectiva de Milton Santos, de modo a construir uma análise que possa contribuir para o crescente debate sobre este tema na área do Serviço Social.
\end{abstract}

Palavras chave: Território. Assistência social. Risco e vulnerabilidade social. CRAS.

\begin{abstract}
:
This article approaches the territorial dimension in the perspective of the Social Work Public Policy. It is built an idea of this dimension as a strategic position in the organization of the Social Work Policy and this perspective requires a new understanding of the families under vulnerability and social risk. The concept of territory overcomes the Geographic boundaries, however, it should still rely on them to build an analytical and interventionist perspective in which force fields and social relationships are organized in a live place with dynamic movements. The acknowledgment of territory may be a way to establish different priorities in the field of public policies. In this article, we highlight the territory used according to Milton Santos's perspective to make an analysis which may contribute to the increasing debate about this topic in the Social Service area.
\end{abstract}

Key Words: Territory. Social work. Social vulnerability. CRAS.

\footnotetext{
* Assistente Social. Mestranda em Geografia pela UNESP, campus Presidente Prudente/SP. Especialista em Gestão Pública Municipal pela UEM (Universidade Estadual de Maringá).

** Docente do Curso de Pós-Graduação em Geografia da UNESP, Campus Presidente Prudente/SP.
} 


\section{Introdução}

O esforço coletivo para a incorporação da dimensão territorial, na perspectiva da Política Nacional de Assistência Social (BRASIL, 2004) e do Sistema Único de Assistência Social (BRASIL, 2005), ainda não alcançou uma suficiente problematização que dê conta da magnitude de seus significados para a apropriação, não apenas no âmbito conceitual, mas que faça sentido para a prática da formulação, implementação e avaliação de políticas públicas que visem ao enfrentamento e prevenção de situações de vulnerabilidades e riscos sociais (LINDO, 2010).

Com base em tal questão norteadora, este artigo tem início com a apresentação de um debate conceitual sobre território, e explora, a partir daí, sua relevância para a consolidação do SUAS e das propostas de ações públicas de assistência social formuladas e implementadas territorialmente. Ganha relevância, então, o CRAS - Centro de Referência da Assistência Social, com base nos princípios de descentralização, de superação da fragmentação das ações e de busca pela universalidade de cobertura. Porém, como será visto, problematiza-se a necessária superação de um reducionismo analítico que teima em considerar apenas as ideias de localização e proximidade como suficientes para esse debate.

Do ponto de vista metodológico, reconhece-se, de antemão, o desafio de se reralizar a aproximação e a interação de reflexões oriundas do conhecimento geográfico e do serviço social, em um esforço conjunto que apenas se inicia e deve respeitar os saberes acumulados em ambos os campos de reflexão e ação, mas que precisa, também, superar tradições e trajetórias disciplinares monolíticas. Os pontos de apoio a partir dos quais se sugere que essas "trocas conceituais" possam ser efetivadas são: a contrução de um olhar comum sobre o permanente processo de produção do espaço e os vários sentidos que o uso do território pode assumir no desenvolvimento de políticas públicas.

Além desta Introdução, este artigo está organizado em três seções. A primeira apresenta e problematiza a inserção da dimensão territorial tal como esta comparece na PNAS (BRASIL, 2004) e no SUAS (BRASIL, 2005). A segunda pauta o debate sobre o território como lógica de proximidade do cidadão, reconhecendo a existência de múltiplos fatores sociais, econômicos, políticos e culturais nele presentes. A ênfase recai sobre a proposição e a intencionalidade presentes na política pública a respeito do CRAS - Centro de 
Referência da Assistência Social, com o intuito de contribuir para um debate que ultrapasse as preocupações que se limitam à sua localização. Na terceira, é apresentada uma discussão a respeito do conceito de território e, mais especificamente, das contribuições de Milton Santos (1992, 1997, 2001, 2002a, 2002b, 2007), a partir das quais são articuladas, ainda, as contribuições de Dirce Koga $(2003,2005)$. Realce especial é conferido ao território usado e a seus desdobramentos analíticos para os fins aqui buscados. Por fim, a última seção apresenta uma síntese e pontua algumas questões que permanecem nessa agenda de discussões.

\section{Território: um conceito estratégico}

A Norma Operacional Básica - NOB-SUAS/2005 - define com detalhamento as novas lógicas de organização, gestão e provisão no campo das ações continuadas de assistência social. Dentre os elementos essenciais dessa formulação, destaca-se o território como base de organização do sistema, cujos serviços devem obedecer à lógica de proximidade do cidadão e localizar-se em territórios de incidência de vulnerabilidade e riscos para a população (BRASIL, 2005, p. 43).

A perspectiva territorial que passa a ser buscada e incorporada pelo SUAS/2005 representa uma mudança paradigmática de relevância. As ações públicas da área da assistência social, destacando-se as desenvolvidas nos CRAS, devem ser, segundo a citada Norma, planejadas territorialmente, tendo em vista a superação de sua fragmentação, o alcance da universalidade de cobertura, a possibilidade de planejamento e monitoração da rede de serviços e a realização da vigilância social das exclusões e estigmatizações presentes nos territórios de maior incidência de vulnerabilidade (BRASIL, 2008).

O território passa, assim, a ser considerado como base de organização do SUAS/2005, mas não basta tal constatação. Faz-se necessário problematizar como esse conceito é compreendido, problematizado e utilizado não apenas na Norma, mas em outros documentos oficiais que a subsidiam. Assim, por exemplo, é possível extrair da seguinte citação, encontrada em um documento destinado a difundir a Norma e a capacitar gestores de diferentes níveis de gestão do SUAS, uma primeira visão sobre como o território vem sendo pensado: 
O território representa muito mais do que o espaço geográfico. Assim, o município pode ser considerado um território, mas com múltiplos espaços intraurbanos que expressam diferentes arranjos e configurações socioterritoriais. Os territórios são espaços de vida, de relações, de trocas, de construção e desconstrução de vínculos cotidianos, de disputas, contradições e conflitos, de expectativas e de sonhos, que revelam os significados atribuídos pelos diferentes sujeitos (BRASIL, 2008, p. 54).

Por um lado, observa-se a compreensão clara do território como resultado e produto de sujeitos que, em suas ações sociais, o produzem. Palavras como "vida", "trocas", "vínculos cotidianos", "contradições e conflitos" realçam a dimensão processual presente nos processos de produção do território, ao mesmo tempo que sinalizam, também, a necessária apreensão destas dinâmicas no plano da análise. Por outro lado, entretanto, restam questões a serem problematizadas, como a referência a município (unidade da federação), a espaços intra-urbanos (como se fora apenas uma subdivisão do primeiro e não uma escala de análise) e às suas articulações.

A questão acima não se evidencia como trivial e pode ser assim enunciada para que, paulatinamente, seja discutida ao longo deste artigo: para além de divisão de áreas, limites e fronteiras determinados em lei, ou ainda, de uma zona ou área de uma cidade, como problematizar a questão territorial na Política da Assistência Social, de modo a ssumir e revelar, ao mesmo tempo, seu componente multiescalar? Como conceber e trabalhar com e em múltiplas escalas geográficas como estratégia analítica e de ação? ${ }^{1}$

Koga e Nakano (2005) oferecem uma pista para uma primeira resposta ao afirmarem que é preciso compreender que diferentes segmentos da população podem apresentar configurações muito distintas a depender do lugar/lugares onde se encontram e onde se concretizam como sujeitos coletivos de ações político-territoriais, ao que se pode acrescentar: em múltiplas escalas, na medida em que tais ações e lugares lembrados se manifestam em, e a partir de distintas escalas, como regional, urbana, nacional, metropolitana ou, até mesmo, global.

\footnotetext{
${ }^{1} \mathrm{O}$ debate sobre as escalas geográficas, sua produção e permanentes interações, bem como sua capacidade de jogar luz sobre processos complexos e em permanente movimento não serão aqui abordados. Outrossim, uma vez que subsidia o conjunto das reflexões aqui formuladas, sugerimos a leitura de Smith (1998); Brandão (2008); Castro (1995) e Melazzo e Castro (2008), dentre outros.
} 
Os autores citados, ao elaborarem sobre as potencialidades que se abrem a partir do momento em que o território passa a comparecer como tema de debate e como estratégia de ação para a Assistência Social, afirmam que:

\begin{abstract}
Desdobra-se para as políticas públicas, e em particular para a Política de Assistência Social, a necessidade de compreender as particularidades de cada território e incorporar a abordagem territorial na formulação, implementação, monitoramento e avaliação das políticas públicas. Para tanto, é fundamental pensar as potencialidades ativas dos territórios na constituição de processos e relações sociais e de poder (KOGA; NAKANO, 2005, p.68).
\end{abstract}

São reforçadas, assim, as questões anteriormente formuladas: quando se trata de conceber o território a partir de "relações sociais e de poder", não há como deixar de se inquirir sobre as escalas de tais relações. Ou seja, é preciso colocar ênfase nos próprios processos de produção e reprodução social, que articulam determinantes múltiplos (econômicos, culturais, políticos) em suas sinergias e que, necessariamente, são resultantes também de processos desencadeados em múltiplas escalas.

A PNAS/2004, por seu lado, pressupõe, em suas diretrizes, a territorialização como um dos princípios que compõem uns dos principais mecanismos de sustentação para a organização do SUAS/2005, pois leva em consideração a heterogeneidade e a desigualdade sócio-territorial presente no país (BRASIL, 2004, 2005). Com isso, enfatiza que, "ao invés de metas setoriais a partir de demandas ou necessidades genéricas, trata-se de identificar os problemas concretos, as potencialidades e as soluções, a partir de recortes territoriais" (BRASIL, 2004, p. 37).

Do ponto de vista operacional, o documento posterior avança um pouco mais, ao afirmar que a perspectiva territorial incorporada pelo SUAS/2005:

[...] representa uma mudança paradigmática de relevância e há a possibilidade de planejar e monitorar a rede de serviços, realizar a vigilância social das exclusões e estigmatizações presentes nos territórios de maior incidência de vulnerabilidade e carecimentos (BRASIL, 2008, p.53).

Tanto no primeiro quanto no segundo documento, ficam ressaltados o uso das expressões "recortes territoriais" e "territórios de maior incidência de vulnerabilidade e carecimentos", o que sinaliza a intencionalidade da política pública em fugir de qualquer 
pretensão homogeneizadora, reconhecendo desigualdades e diferenciações que devem ser incorporadas por ela.

Trata-se, assim, de tomar tal intencionalidade como ponto de partida para uma reflexão que faça avançar concretamente e de maneira a incorporar a complexidade do conceito de território na análise e na ação da Política Pública da Assitência Social.

\section{Do território como lógica de proximidade do cidadão: os CRAS e sua importância}

A perspectiva territorializada dos serviços e benefícios da assistência social representa uma mudança importante a ser, adequadamente, apropriada, tal como visto, e advoga-se, aqui, que, com o princípio da territorialização, há múltiplos ganhos para a gestão e, especialmente, para a população potencialmente beneficiária da Política de Assistência Social.

Porém, não há como ressaltar que, na maior parte das vezes, tal territorialização ou perspectiva territorial tem sido reduzida a apenas uma de suas dimensões: a que trata de articulá-la à lógica da localização e da proximidade, compreendendo que os serviços sociais, ao serem implementados próximos ao cidadão, podem antecipar respostas às suas necessidades e facilitar o acesso, em uma perspectiva de proteção social pró-ativa.

Nessa perspectiva é que se insere a valorização e a importância do fortalecimento do território pensado como localização e como elemento essencial para a efetivação do acesso à proteção social, no que se refere aos serviços socioassistenciais ofertados nos CRAS, pois possibilita uma proximidade entre o poder público e a população.

Vale destacar o avanço que o estabelecimento dessa proximidade pode proporcionar para uma maior compreensão das relações estabelecidas pela Política de Assistência Social nos e entre os territórios considerados de risco e vulnerabilidade social.

Segundo definição do Ministério de Desenvolvimento Social e Combate à Fome (MDS), embasada na PNAS/2004, o CRAS é uma unidade pública da Política de Assistência Social, de base municipal, integrante do SUAS, localizado em áreas com maiores índices de vulnerabilidade e risco social, destinado à prestação de serviços e programas socioassistenciais de proteção social básica às famílias e indivíduos e à articulação destes serviços no seu território de abrangência, em uma atuação intersetorial com a perspectiva de potencializar a proteção social (BRASIL, 2004). 
Somente a título de esclarecimento, é possível afirmar que uma abordagem afinada com a concepção de vulnerabilidade orienta-se para os processos, pois examina as estratégias que as famílias utilizam para lidar com os riscos e a queda de bem estar. Vulnerabilidade articula-se com a ideia de risco e, na literatura, esses termos são, frequentemente, abordados de forma conjunta. No campo da proteção social, o foco orientado pela abordagem da vulnerabilidade e dos riscos está nas estratégias utilizadas pelas famílias que fazem com que algumas escapem da pobreza e outras se perpetuem nela. Isso remete à contribuição possível e necessária das políticas públicas para o fortalecimento das capacidades de indivíduos, famílias e regiões para o enfrentamento e a superação da condição de vulnerabilidade.

Kaztman (1999) trata do conceito de vulnerabilidade social como o confronto entre os recursos acumulados (ou sua ausência) por indivíduos, famílias e comunidades e as oportunidades acessíveis para empregá-los, o que permite identificar as diferentes situações de vulnerabilidade social a que estes/as estão submetidos/as.

Kaztman e Filgueira (2006, p. 71) têm trabalhado com o conceito de vulnerabilidade social relacionado aos processos de pobreza e exclusão social, ao afirmarem que:

[...] chamamos de vulnerabilidade ante a pobreza ou a exclusão social as situações que surgem quando as configurações de recursos que controlam e podem movimentar os municípios não são suficientes para aproveitar as estruturas de oportunidade de acesso ao bem estar.

A abordagem da vulnerabilidade social mostra-se relacionada ao acesso ao bem estar social que os autores acima citados denominam de "estruturas de oportunidade de acesso ao bem estar".

O reconhecimento socioterritorial da vulnerabilidade social exige dos municípios investimentos em estruturação e informatização para a produção de informações mais desagregadas sobre a realidade socioeconômica, política e cultural.

Cabe ressaltar uma reflexão sobre a noção de risco social e diferenciá-la das teses que intitulam a sociedade moderna como sociedade de risco, em função do alto grau de incerteza que comanda o futuro da civilização. Para Castel (2005, p. 61), "um risco no 
sentido próprio da palavra é um acontecimento previsível, cujas chances de que ele possa acontecer e o custo dos prejuízos que trará podem ser previamente avaliados."

Portanto, para identificar a instalação de serviços socioasssistenciais nos territórios vulneráveis, é necessário identificar os riscos a que estão expostos os grupos que ali vivem, para que se possa organizar serviços e programas para preveni-los, evitando que se instalem, ou para atenuá-los, no caso de já terem provocado agravos ou sequelas individuais e sociais. Assim, para Sposati (2006):

O dimensionamento dos riscos e das vulnerabilidades, como condições prioritárias na assistência social, não retira a preocupação com o desenvolvimento da atenção ao quase risco ou com a descoberta de iniciativas inibidoras da presença ou do agravamento da vulnerabilidade. Só assim a assistência social, como política pública, alcançará sua efetividade (SPOSATI, 2006).

Trata-se de riscos a que estão expostos indivíduos, famílias, coletividades e classes sociais que se encontram fora do alcance da rede de segurança propiciada pela proteção social pública e que, por isso, vivem em situação de pobreza e risco social gerados por uma cadeia complexa de fatores.

Segundo Holzman e Jorgensen (2003), risco pode ser entendido como uma variedade de situações que englobam: os riscos naturais (como terremotos e demais cataclismos), os riscos de saúde (doenças, acidentes, epidemias, deficiências), os riscos ligados ao ciclo de vida (nascimento, maternidade, velhice, morte, ruptura familiar), os riscos sociais (crime, violência doméstica, terrorismo, gangues, exclusão social), os riscos econômicos (choques de mercado, riscos financeiros), os riscos ambientais (poluição, desmatamento, desastre nuclear) e os riscos políticos (discriminação, golpes de estado, revoltas), tal como sistematizados pela unidade de proteção social do Banco Mundial. Os indivíduos e as famílias posicionam-se diferentemente quanto à capacidade de resposta aos riscos e às mudanças do entorno.

O enfoque da vulnerabilidade e dos riscos permite uma ponte mais direta com o campo das políticas públicas, ao explicitar as diferentes estratégias que devem ser desenvolvidas para fazer frente a riscos específicos e fortalecer a capacidade de resposta das famílias para a redução de sua vulnerabilidade. Vulnerabilidade relaciona-se, por um lado, com a exposição ao risco, e, por outro, com a capacidade de resposta, material e/ou 
simbólica, que indivíduos, famílias e comunidades conseguem dar para fazer frente ao risco ou ao choque (que significa a materialização do risco). As políticas e os programas inseremse nesse campo, como elementos que podem fortalecer a capacidade de resposta das famílias e de seus membros, de modo a reduzir seu grau de vulnerabilidade.

Segundo Alwang, Siegel e Jorgensen (2001, p. 3), é possível dar respostas aos riscos, basicamente, de duas formas, antes ou depois da ocorrência do evento de risco:

\begin{abstract}
No primeiro caso, as ações podem se dar na perspectiva da prevenção ou na da redução ou mitigação do risco. Na prevenção, a finalidade das estratégias é reduzir a probabilidade de produção de riscos adversos, as quais ocorrem, portanto, antes que se produzam os riscos. Tais estratégias envolvem políticas macroeconômicas, de regulação, de meio ambiente, de educação, de prevenção de epidemias, entre outras. Na perspectiva preventiva da proteção social, as medidas envolvem a redução dos riscos de desemprego, de subemprego e de baixos salários, por exemplo. Na mitigação, as intervenções voltam-se para a redução dos efeitos de riscos futuros e, portanto, tais estratégias situam-se antes da produção dos riscos, à medida que buscam reduzir a repercussão ou os efeitos dos eventos de riscos, caso ocorram. Trata-se de medidas ex ante, que buscam reduzir o impacto do risco, caso este se materialize. Envolvem, entre outras ações, a diversificação da renda, o que significa acesso a gama mais ampla de ativos e mecanismos formais e informais de seguros. Uma vez que os eventos tenham ocorrido, o objetivo é enfrentar os riscos (grifos dos autores).
\end{abstract}

Diante deste entendimento, é importante destacar que as situações de risco e vulnerabilidade ocorrem de forma diferenciada em cada território analisado, dada a heterogeneidade existente no Brasil, e que cada território tem suas especificidades e particularidades. Um mesmo município pode ser constituído para vários territórios (considera-se o território de vulnerabilidade e risco social onde estão - ou deveriam estar - instalados os CRAS, e, consequentemente, os potenciais beneficiários da Política Pública de Assistência Social), cuja população é diferente, tem anseios e perspectivas diversificadas, com características e carências específicas e potencialidades distintas.

A dimensão territorial implica em tratar a cidade e seus territórios como chão das políticas públicas (KOGA, 2003), o que significa um deslocamento para além da setorialidade adotada tradicionalmente, no sentido de abranger o trabalho em rede dos serviços públicos e privados, com destaque para o CRAS, que se organizam nos territórios onde as diversas comunidades vivem e tecem seu cotidiano.

Integra os objetivos do CRAS o desenvolvimento de ações de proteção social básica, de vigilância social e de defesa social e institucional, sempre em uma perspectiva 
territorializada e com o foco na matricialidade sociofamiliar, de acordo com o citado documento.

É na integração desses objetivos que o CRAS desenvolve um novo modelo socioassistencial em consonância com o SUAS/2005, uma ação que integralize a proteção, vigilância e defesa social gera uma proteção social efetiva, movida por processos e estratégias capazes de produzir convívio, pertencimento e autonomia às famílias e aos cidadãos (SÃO PAULO, 2009, p. 18).

Sua característica de espaço público remete a considerá-lo como unidade de possibilidades, de reconhecimentos, de acessos a direitos, de proteção social, de provisões, de acolhimento, de segurança, de estratégias e, principalmente, de referência no que diz respeito ao atendimento da população local.

O CRAS, a partir desses condicionantes, deve materializar a presença do Estado em uma determinada área, possibilitando a democratização do acesso aos direitos e contribuindo para o fortalecimento da cidadania. Além disso, o CRAS deve ser espaço de participação e envolvimento da população, o que possibilita que se transforme em ambiernte potencial para a interlocução entre Estado e Sociedade Civil.

A PNAS/2004 destaca a necessidade de critérios para a escolha da localização para a instalação do CRAS, que deve ser baseada na identificação de famílias e territórios em situação de vulnerabilidade (BRASIL, 2004). Mais ainda, a instalação do CRAS deve buscar a descentralização da assistência social, sendo esse um dos aspectos que the conferem característica de inovação perante as novas proposituras da assistência social.

A gestão do território, a partir do CRAS, busca promover uma atuação preventiva, racionalizar as ofertas e traduzir o referenciamento dos serviços em ações concreta, tornando-se a principal unidade pública de proteção básica e referência para a população local e para os serviços setoriais.

Di Méo (1996, p. 21) ressalta que:

Territorializar é construir e reconstruir sem cessar pelo comportamento do ator social, materialmente e em suas representações: pelo indíviduo e seu grau de poder ou de influência; para o indivíduo é uma alquimia entre o pessoal e o coletivo, onde nosso aparelho cognitivo não pode inventar tudo.

Cabe salientar que a trajetória da Política de Assistência Social é recente e, aos poucos, vem rompendo com a herança de um passado regado de assistencialismo, caridade 
e solidariedade. A introdução do território como foco de atuação dessa política materializa a descentralização das ações e da tomada de decisão, impulsionando a participação dos beneficiários em sua formulação e gestão.

Yazbek (2004, p. 16) afirma que:

\begin{abstract}
A descentralização contribui para o reconhecimento das particularidades e interesses próprios do município e como possibilidade de levar os serviços para mais perto da população. [...] [e] a municipalização aproxima o Estado do cotidiano de sua população, possibilitando-lhe uma ação fiscalizatória mais efetiva, permite maior racionalidade nas ações, economia de recursos e maior possibilidade de ação intersetorial e interinstitucional.
\end{abstract}

De forma sintética, o CRAS deve permitir que sejam estruturadas relações próximas com as famílias e com a comunidade, já que estas são portadoras de identidades, saberes, experiências e de projetos futuros. Outra atribuição, no âmbito da função de gestão do território pelo CRAS, é promover a articulação intersetorial, que deve ser entendida como interação entre setores e saberes, para responder, de forma integrada, a um objeto comum (SÃO PAULO, 2009, p. 26).

No que diz respeito à dinâmica territorial, Santos (1997) afirma que o território só se torna um conceito utilizável para a análise social quando é considerado a partir de seu uso, ou seja, a partir do momento em que é pensado juntamente com os atores que o utilizam. É o uso do território e não o território, em si mesmo, que faz dele um objeto de análise social. É a partir desta perspectiva de Santos que este conceito vem sendo introduzido como uma categoria analítica e de intervenção no campo das políticas sociais brasileiras. A perspectiva de território, proposta por Santos, será tratada e desdobrada na próxima subseção.

Para Sposati (2008), o território é dinâmico, pois, para além da topografia natural, constitui uma "topografia social", decorrente das relações entre os que nele vivem e das relações destes com os que vivem em outros territórios. Território não é gueto, apartação, mas mobilidade. Por isso, discutir medidas de um território é assunto bem mais complexo do que definir sua área, pois implica em considerar o conjunto de forças e dinâmicas que nele operam (SPOSATI, 2008, p. 9).

Para além de uma área na qual pessoas e famílias se localizam e são prestados serviços aos respectivos cidadãos, o território: 
[...] significa articulações sociais, conflitos, cooperações, concorrências e coesões; é produto de tramas que envolvem as construções (formas espaciais), as instituições, as redes multiescalares, as relações sociais e a natureza exterior ao homem; é objetivo-material e subjetivo-imaterial ao mesmo tempo (SAQUET, 2009, p. 88).

Para Saquet (2006), o território é resultado e condição de um processo histórico, em que há relações socioespaciais em diferentes níveis da escala geográfica, que definem e delimitam o espaço a partir das relações de poder e, ao mesmo tempo, podem transpor limites políticos e administrativos através de atividades econômicas e dos meios de comunicação e circulação (SAQUET, 2006, p. 23).

A geografia possui muitos elementos de ordem conceitual, analítica e instrumental que podem contribuir para o desenvolvimento de práticas de assistência social no campo da formulação, implementação e avaliação da política pública, tal como o conhecimento acumulado sobre as escalas geográficas para a análise e para ação, o que pode auxiliar os agentes a se apropriarem, de forma consciente, de instrumentos e estratégias que lhes permitam medir, localizar, analisar e interpretar se os processos de exclusão/vulnerabilidade e as ações de combate implementadas apresentam mudanças ou não, além de identificar a possibilidade de neles intervir de forma planejada e qualificada (LINDO, 2010). Nesse sentido, a aquisição de tais conhecimentos possibilitará que os municípios possam reconhecer e apresentar seus territórios como é previsto no PNAS/2004.

Assim, pode-se afirmar que as políticas públicas se desdobram nesses territórios onde são tomadas decisões que se dão "por intermédio de atores governamentais, compreendendo atos que viabilizam agendas de inovação em políticas ou que respondem a demandas de grupos de interesse." (COSTA, 1998, p. 7).

Como a cidade é palco de relações sociais e de uma grande diversidade de ações que nela atuam segundo interesses diversos, é possível pensar que ela não é homogênea sob vários aspectos e, portanto, seus vários lugares não devem ser tratados da mesma forma. Desse modo, deve-se compreender a "cidade enquanto um território múltiplo, como o chão concreto das políticas, a raiz dos números e a realidade da vida coletiva." (KOGA, 2003, p. 33). 
Para Felix (2011), é no território que se processam as várias desigualdades e, pelo fato deste ser um espaço dinâmico, devido às relações sociais contidas nele, possue um desenvolvimento próprio, que evidencia as diferentes especificidades dos conflitos sociais de cada um dos lugares que o compõem, assim como, de seus reflexos no restante da cidade. Além disso, somente quando se trata o território sob a ótica social é que se evidenciam as diferenças agudas existentes entre os indivíduos pobres e os não pobres, que moram, respectivamante, em lugares pobres e em lugares não pobres.

Essa discussão ganha valor quando enriquecida com a compreensão possibiliatada por uma coleta de dados sobre um determinado lugar, o que é fundamantal para uma melhor apreensão da realidade para o desenvolvimento de políticas sociais.

Felix (2011) afirma que a dinâmica interna dos distintos "espaços sociais" pode apresentar vários elementos que constituem dados eficazes para a definição da redistribuição de investimentos públicos, que, ao serem trabalhados, poderão se transformar em indicadores valiosos para o combate à exclusão. Tal multiplicidade se dá no momento em que várias culturas se agregam em um mesmo espaço, culturas essas advindas da grande mobilidade existente em áreas mais vulneráveis.

Koga (2003) traduz esta questão quando diz que as políticas públicas, em geral, tendem a homogeneizar o espaço, desconsiderando as particularidades e a dinâmica peculiar de cada um. Nessa relação, o espaço não é somente uma área fria, estática, mas é, efetivamente, um elemento para análise, móvel e rico em detalhes.

Nesse contexto, Santos (2001, p. 19) complementa:

[...] a linguagem cotidiana freqüentemente confunde território e espaço. [...] Para uns, o território viria antes do espaço; para outros, o contrário é que é verdadeiro. Por território entende-se geralmente a extensão apropriada e usada. Mas o sentido da palavra territorialidade como sinônimo de pertencer àquilo que nos pertence [...] esse sentimento de exclusividade e limite ultrapassa a raça humana e prescinde da existência do Estado. Assim, essa ideia de territorialidade se estende aos próprios animais, como sinônimo de área de vivência e de reprodução. Mas a territorialidade humana pressupõe também a preocupação com o destino, a construção do futuro, o que entre os seres vivos, é privilégio do homem. Num sentido mais restrito, o território é um nome político para o espaço de um país. 
Nesse sentido, o território é a extensão apropriada e usada, vista como unidade e diversidade; é uma terminologia política para os vários espaços sociais de um país, palco das ações humanas.

Para Koga (2003), é no território que o direito a ter direito será expresso ou negado, abnegado ou reivindicado. É a partir do território que se concretizam os jogos de interesse que acabam por construir diversos territórios, ao longo do tempo-espaço, os quais, muitas vezes, se sobrepõem uns aos outros. É desse ponto de vista que se pode compreender o território na perspectiva integradora de Haesbaert (2004), ou seja, como revelador de parte ou de todas as dimensões: sociais, políticas, culturais, econômicas e, até mesmo, ambientais. O autor explica sua compreensão de forma articulada, conectada, integrada a outros territórios, assim como, pela perspectiva relacional, segundo a qual são consideradas as relações sócio-históricas com suas diferenças espacializadas em um determinado tempo. Desse modo, o território é fruto de uma relação complexa entre os processos sociais e o espaço material e imaterial.

\section{Refexões sobre o conceito de território e de território usado}

Neste estudo, o território é entendido como uma objetivação multidimensional da apropriação social do espaço (CARA, 1996), onde se estabelecem relações de poder entre os vários grupos sociais e instituições (ANDRADE, 1996). Nesse sentido, o conceito de território não se vincula, necessariamente, à propriedade da terra, mas à sua apropriação, que se associa ao controle de fato, efetivo, por vezes, legitimado, por parte de instituições ou grupos sobre um dado segmento do espaço (CORRÊA, 1996, p. 251), o que o torna, portanto, revestido de uma dimensão política.

Isso pode ser notado nos diversos campos do saber, pois o conceito de território esteve, quase sempre, condicionado às relações de poder que se estabelecem entre os grupos sociais e entre estes e a natureza (RAFFESTIN, 1993). Ou seja, a sua definição se faz pela apropriação e dominação de uma área por um determinado grupo social, não bastando, assim, apenas o conhecimento dos dados e das estruturas físicas do espaço geográfico, mas, principalmente, como os sujeitos sociais exercem a vida no território. 
O território constitui um conceito subordinado a outro, mais abrangente, o de espaço, que diz respeito à organização espacial, sendo, portanto, o espaço revestido da dimensão política (CORRÊA, 1996).

O espaço, dessa maneira, surge como processo e produto de relações sociais, que se realiza enquanto uma instância social (SANTOS apud BORTOLOZZI; FARIA, 2009, p. 34), podendo ser definido como um conjunto indissociável, solidário e, também, contraditório de sistemas de objetos e de sistemas de ações, não considerados isoladamente, mas como um quadro único no qual a história se dá (SANTOS, 2004, p. 63). Somado a isso, não é neutro, uma vez que nele há um acúmulo de interesses divergentes imbricados em cada parte que o compõe (ARAÚJO; BEZERRA; VALENÇA, 2010, p. 3). Nesse sentido, Lefebvre esclarece que o espaço:

Não é um objeto científico descartado pela ideologia ou pela política; ele sempre foi político e estratégico. Se esse espaço tem um aspecto neutro, indiferente em relação ao conteúdo, portanto "puramente" formal, abstrato de uma abstração racional, é precisamente porque ele está se ocupando, ordenado, já foi objeto de estratégias antigas, das quais nem sempre se encontram vestígios. $O$ espaço foi formado, modelado a partir de elementos históricos ou naturais, mas politicamente. O espaço é político e ideológico. É uma representação literalmente povoada de ideologia (LEFEBVRE apud ARAÚJO; BEZERRA; VALENÇA, 2010, p. 3).

O espaço geográfico é possuidor de uma forma, isto é, de uma organização que se pretende adequar ao funcionamento da sociedade. Essa forma é definida ideologicamente, em um determinado bloco histórico, que corresponde à hegemonia de determinada classe social, e é no âmbito do Estado que se estabelecem os relacionamentos entre interesses divergentes que darão o conteúdo para as formas espaciais, que poderão ser mais ou menos excludentes, ou segregacionistas, dependendo das características do bloco histórico (SANTOS, 2008, p. 49).

Ao abordar o espaço nessa perspectiva, Santos permite pensá-lo para além das geometrias, pois, na medida em que coloca o papel central das relações sociais na sua produção, ele mesmo se torna uma categoria relacional, que se realiza como processo, movimento ou fluxo. Isso ocorre porque, as formas "estão sempre mudando de significação, na medida em que o movimento social lhes atribui, a cada momento, frações 
do todo social [...]" (SANTOS, 1997, p. 2). Essa linha de pensamento é corroborada por Brito (2002, p. 12), segundo o qual território é:

[...] uma fração desse espaço [espaço geográfico], na qual determinados agentes sociais se relacionam com o intuito de reproduzi-lo segundo seus próprios interesses (condição que manifesta o uso do território), mediante consensos estabelecidos tácita e/ou formalmente (grifo do autor).

O território é determinado pelas diferentes funções espaciais ou pelos diferentes usos espaciais, assim, não é possível entendê-lo ignorando as relações políticas e econômicas que se estabelecem no modelo capitalista de produção (SANTOS, 2007). Ao entender essas relações, que se desdobram em diferentes funções e usos espaciais, tornase possível delimitar, territorialmente, um espaço, para a implementação de políticas públicas.

O conceito de território é vinculado às relações de poder e embasam as complexas relações sociais que se moldam no território, cujos acordos, definidos pelos diferentes atores sociais, têm como fruto as assimetrias no exercício do poder. Em outras palavras, existe um território usado que, ao unir elementos dentro de um processo, poderá alcançar um território mediado pelas relações de poder na perspectiva de Arendt (1985), ou seja, que visa a uma maior justiça socioespacial.

O território não é uma entidade pura, não é apenas natureza, não é apenas político, não é apenas econômico ou cultural, tampouco é homogêneo. O território usado constitui-se de formas e ações e é sinônimo de espaço humano (SANTOS, 1994).

Para Koga (2003, p. 35-36):

O uso do território pelos sujeitos e a relação entre território e população, o conceito de território se constrói a partir da relação entre território e as pessoas que dele se utilizam. Esta indivisibilidade hoje se mostra com uma particularidade extremamente fecunda quando observamos a intensa dinâmica da população nos territórios. A relação inseparável entre território e sujeito ou população, permite uma visão da própria dinâmica do cotidiano vivido pelas pessoas.

Assim, Santos (2000, p. 122) relaciona o cotidiano com o local:

Na vida de todos os dias, a sociedade global vive apenas por intermédio das sociedades localmente enraizadas, interagindo com o seu próprio entorno, 
refazendo todos os dias essa relação e, também, sua dinâmica interna, na qual, de um modo ou de outro, todos agem sobre todos.

É nessa perspectiva que o território ultrapassa sua circunscrição político-jurídica enquanto Estado-Nação e, por outro lado, não se restringe ao âmbito do chamado lugar, pois este, diferentemente do território, extingue a distância. É da sua posição limitada e hermética que surge sua identidade como tal (KOGA, 2003).

Di Méo (1998) ressalta que, entre lugar e território, a diferença se apresenta, mais frequentemente, quanto à escala e à compreensão geográfica. O território, geralmente, abstraído, idealizado, vivido e sentido mais que visualmente, referenciado e circunscrito (quando não se trata de essência estritamente política), engloba os lugares que se singularizam, em sua diferença, por seu valor de uso e por seu alcance real.

Essa apropriação do território pelo homem, ou seja, seu uso, está presente em diferentes análises, que apontam para o aspecto dinâmico do território e sua constituição relacional intrínseca entre o homem e o espaço. Milton Santos tem enfatizado a categoria território usado como concretização dessa relação dinâmica (SANTOS; SILVEIRA, 2001).

Pode-se afirmar que o conceito de território é polissêmico, e o fato de se tratar de uma categoria interdisciplinar (MONKEN; BARCELLOS apud BORTOLOZZI; FARIA, 2009) permite ainda que este possa ser compreendido enquanto apropriação social, com diferentes nuances - culturais, políticas e economicas. É nessa perspectiva que esse conceito ganha dinamicidade, alterando-se a partir do jogo conflituoso de poder, próprio das relações sociais, tanto no que se refere às escalas quanto às funções que cada recorte territorial admite.

A citada polissemia do conceito de território reside nas várias possibilidades de interpretação, que vão desde seu entendimento pautado, estritamente, pela base material - uma extensão da superfície da terra -, até o definido pelo estado de potência, relacionado aos limites de um Estado-Nação ou mais além, o que demonstra as variadas abordagens desse conceito.

Interessa, aqui, particularmente, a abordagem que permite estabelecer as relações entre os territórios em diferentes escalas geográficas. Assim, é possível transitar entre as escalas geográficas: do local - acesso aos serviços, qualidade de vida, moradia, 
transporte etc. - às escalas nacionais ou globais - políticas públicas, relações econômicas internacionais etc. (BORTOLOZZI; FARIA, 2009).

Conforma-se, portanto, a possibilidade de, sem desconsiderar por um lado, ou reduzir por outro, pensar a localização ou proximidade como um dos componentes da interpretação do território: sem desconsiderar, pois se refere a uma dimensão não desprezível da escala local, onde se realiza a vida e se reproduzem, desigualmente, as relações sociais entre grupos e segmentos também, desigualmente, localizados; e sem reduzir a dimensão territorial da política pública apenas à lógica da proximidade, que poderia ser, aqui, associada ao CRAS e a seu potencial transformador, sem reconhecer a pluriescalaridade dos processos presentes em cada área.

É a partir desse ponto e com a ressalva acima em mente que se torna possível uma aproximação à formulação proposta por Santos (2007, p. 22):

O território tem que ser entendido como o território usado, não o território em si. O território usado é o chão mais a identidade. A identidade é o sentimento de pertencer àquilo que nos pertence. O território é o fundamento do trabalho; o lugar da residência, das trocas materiais e espirituais e do exercício da vida.

Nessa citação, Milton Santos elucida o valor do território, pois o relaciona à identidade e ao sentimento de pertencer, deixando clara a relação de uso do território, o que, necessariamente, implica em reconhecer os sujeitos e agentes e seus diferentes usos.

A citação também permite afirmar que o território não é estático, pois tem seus usos e significados alterados pela dinâmica da sociedade que, ao longo do tempo, redefine as relações de poder (materiais e simbólicas) entre os grupos sociais e seus espaços. Assim, pensar políticas públicas na ótica do território e dos vínculos sociais não significa pretender a homogeneização das condições sociais e das realidades cotidianas, mas buscar uma visão estratégica para a otimização dos esforços públicos.

Santos, Souza e Silveira (1996) defende que, ao se atentar para o uso do território, pode-se desvendar os diferentes interesses dos diversos agentes sociais que, ao se relacionarem entre si, atuam na formação dos territórios. Por isso, o território usado é composto pela interação permanente de objetos e ações, sinônimo de espaço humano, espaço habitado (SANTOS, 1994). 
Em um diálogo com o autor, que aponta a relação de uso no território, vale destacar a necessidade de considerá-lo a partir das interações sociais, afetivas, de solidariedade, de amizade, de poder, de conflitos, que trazem um significado vivo para o território, explicitando a vivência e a experiência cotidiana das pessoas que nele vivem.

Assim, é possível compreender que a plena realização do homem, material e imaterial, não depende apenas das relações econômicas hegemônicas. Ela deve resultar de um quadro de vida, material ou não material, que inclua a economia e a cultura, pois ambas influenciam o território e este não têm apenas um papel passivo, mas constitui um dado ativo, que deve ser considerado como fator e não, exclusivamente, como reflexo da sociedade. É no território, tal como ele é atualmente, que a cidadania se dá tal como é hoje, isto é, incompleta (SANTOS, 2007, p. 18).

Com isso, entender o território não é apenas estudar o espaço geográfico como um dado inerte. Este estudo exige a compreensão das relações sociais e dos padrões de civilização adotados na contemporaneidade histórica. Exige também o entendimento do processo cultural construído em sociedades nacionais e em escala mundial, de modo a compreender como a cidadania se processa nos espaços de reprodução da vida (DINIZ, 2012). Ou seja, exige a compreensão dos processos em suas múltiplas escalas para que estes possam ser sintetizados para uma leitura adequada e complexa do território.

Silveira (2011) afirma que o território revela as ações passadas, já congeladas nos objetos e normas, assim como, as ações presentes, ou seja, as que estão a caminho de se realizar, capazes de conferir sentido ao que preexiste. As bases materiais e imateriais, historicamente, estabelecidas são apenas condições. Seu verdadeiro significado advém das ações sobre elas realizadas. O território usado é, por isso, movimento permanente.

Nesse movimento permanente é que se torna possível e necessária a identificação de deficiências, carências, riscos e vulnerabildiades, para a formulação de políticas sociais, também passíveis de serem consideradas como um uso do território.

\section{Considerações finais}

Em busca da compreensão e apreensão do conceito de território e seus desdobramentos, com base na perspectiva de Milton Santos, numa aproximando com a Política de Assistência Social, destaca-se, aqui, a possibilidade (ou necessidade) de articular 
o território (e seu uso) às pessoas e ao cotidiano destas, pois não é possível analisar e problematizar o conceito de território e sua incorporação na Política de Assistência Social sem explicitar as múltiplas escalas geográficas que produzem as diferentes dimensões da vida social.

A discussão, aqui tratada, destaca que a dimensão territorial deve fortalecer a lógica de proteção social, enquanto direito de cidadania, voltada para a prevenção de vulnerabilidades e riscos sociais, de modo a fortalecer os vínculos sociais e a capacidade de participação política, para além de uma localização ou proximidade do CRAS, apenas. Isto não significa, entretanto, que o CRAS não seja importante. Trata-se de um equipamento público fundamental que deve garantir a presença dos direitos sociais, de maneira descentralizada, como unidade de possibilidades de acesso aos direitos de proteção social e de efetivação da cidadania, e como referência no atendimento da população local, reconhecendo os diferentes processos que, em múltiplas escalas, ali se cruzam.

A configuração de uma política pública, territorialmente, articulada não se restringe à imposição ou transposição de uma lógica política administrativa para os territórios, mas deve ser baseada no reconhecimento das capacidades coletivas dos territórios enquanto espaços de vida e vivência com características políticas, econômicas e culturais.

\section{Referências}

ALWANG, J.; SIEGEL, P. B.; JORGESEN, S. Vulnerability: a view from different disciplines. Washington: World Bank, June 2001. (Social Protection Discussion Paper Series n. 0115).

ANDRADE, M. C. de. Territorialidades, desterritorialidades, novas territorialidades: os limites do poder nacional e do poder local. In: SANTOS, M.; SOUZA, M. A.; SILVEIRA, M. L. Território: globalização e fragmentação. 2. ed. São Paulo: Hucitec, 1996.

ARAÚJO, T.; VALENÇA, D.; BEZERRA, H. Direito à moradia e movimentos sociais: uma experiência do MLB em Natal/RN. In: ENCONTRO ANUAL DA ANDHEP, 6., 2010, Brasília.

ARENDT, H. A condição humana. Tradução de Roberto Raposo. Rio de Janeiro: Forense Universitária, 1985.

BORTOLOZZI, A.; FARIA, R. M. de. Espaço, território e saúde: contribuições de Milton Santos para o tema da geografia da saúde no Brasil. Revista $R A^{\prime} E G A$, Curitiba, n. 17, 2009. 
BRANDÃO, C. Desenvolvimento, territórios e escalas espaciais: levar na devida conta as contribuições da economia política e da geografia crítica para construir a abordagem interdisciplinar. In: RIBEIRO, M.T.F.; MILANI, C. R. S. (Org.). Compreendendo a complexidade sócio-espacial contemporânea: o território como categoria de diálogo interdisciplinar. Salvador: Ed. UFBA, 2008.

BRASIL. Ministério do Desenvolvimento Social e Combate à Fome. CapacitaSuas SUAS: configurando os eixos de mudança. Brasília: Instituto de Estudos Especiais da Pontifícia Universidade Católica de São Paulo, 2008. v. 1.

BRASIL. Ministério do Desenvolvimento Social e Combate à Fome. Norma Operacional Básica da Assistência Social - NOB/SUAS. Brasília, 2005.

BRASIL. Ministério do Desenvolvimento Social e Combate à Fome. Política Nacional de Assistência Social. Brasília, 2004.

BRITO, C. C. T. Revisitando o conceito de território. Revista de Desenvolvimento Econômico, Salvador, n. 6, p. 12-20, jul. 2002.

CARA, R. B. Territorialidade e identidade regional no sul da Província de Buenos Aires. In: SANTOS, M.; SOUZA, M. A.; SILVEIRA, M. L. Território: globalização e fragmentação. 2. ed. São Paulo: Hucitec, 1996. p. 261-269.

CASTEL, R. A insegurança social: o que é ser protegido? Rio de Janeiro: Vozes, 2005.

CASTRO, I. E. O problema da escala. In: CASTRO, I. E.; GOMES, P. C. C.; CORRÊA, R. L. (Org.). Geografia: conceitos e temas. Rio de Janeiro: Bertrand Brasil, 1995.

CORRÊA, R. L. Territorialidade e corporação: um exemplo. In: SANTOS, M.; SOUZA, M. A.; SILVEIRA, M. L. Território: globalização e fragmentação. 2.ed. São Paulo: Hucitec, 1996. p. 251-256.

COSTA, N. R. Políticas públicas, justiça distributiva e inovação: saúde e saneamento na agenda social. São Paulo: Hucitec, 1998.

DI MÉO, G. Les territoires Du quotidien. Paris: L'Harmattan, 1996.

Géographie sociale et territoires. Paris: Natha, 1998.

DINIZ, R. A. Territórios, sociabilidades e territorialidades: o tecer dos fios na realidade dos sujeitos dos distritos de Perus e Anhanguera da cidade de São Paulo. 2012. Dissertação (Mestrado) - Pontifícia Universidade Católica de São Paulo, São Paulo.

FELIX, M. R. S. A. O território social: uma nova abordagem para a implentação de ações de políticas públicas. Disponível em:

<http://www.favelaeissoai.com.br/upload/territ\%F3rio\%20social\%20revisto2.pdf>. Acesso em: 12 ago. 2011. 
HAESBAERT, R. Des-caminhos e perspectivas do território. In: RIBAS, A. D.; SPOSITO, E. S.; SAQUET, M. A. Território e desenvolvimento: diferentes abordagens. Francisco Beltrão: UNIOESTE, 2004. p. 87-120.

HOLZMANN, R.; JORGENSEN, S. Manejo social del riesgo: un nuevo marco conceptual para la Protección social y más allá. Revista Facultad Nacional de Salud Pública, Colombia, v. 21, n.1, p. 73-106, 2003.

KAZTMAN, R. (Coord.). Activos y estructuras de oportunidades: estudios sobre las raíces de la vulnerabilidad social en Uruguay. Montevideo: ECLAC Office, United Nations Development Programme, 1999.

KAZTMAN, R.; FILGUEIRA, F. As normas como bem público e privado: reflexões nas fronteiras do Enfoque ativos, vulnerabilidades e estrutura de oportunidades (Aveo). In: CUNHA (Org). Novas metrópoles paulistas: população, vulnerabilidades e segregação. Campinas: NEPO, Sitta, 2006.

KOGA, D. Medidas de cidades: entre territórios de vida e territórios vividos. São Paulo: Cortez, 2003.

KOGA, D. O território e suas múltiplas dimensões na política de assistência social. Cadernos de estudos: Desenvolvimento Social em Debate, Brasília, n. 2, p. 17-33, dez. 2005.

KOGA, D.; NAKANO, K. Perspectivas territoriais e regionais para políticas públicas brasileiras. In: ABONG NAS CONFERÊNCIAS 2005 - Criança e Adolescente, Assistência Social, 2005, Brasília. Cadernos... Brasília: Abong, 2005. p. 68-74.

LINDO, P. V. F. Geografia e Política de Assistência Social: territórios, escalas e representações gráficas entre políticas públicas. 2010. Dissertação (Mestrado) Universidade Estadual Paulista, Faculdade de Ciências e Tecnologia, Presidente Prudente.

MELAZZO, E. S.; CASTRO, C. A. A escala geográfica: noção, conceito ou teoria? Terra Livre, Presidente Prudente, v. 2, p. 133-142, 2008.

RAFFESTIN, C. Por uma geografia do poder. São Paulo: Ática, 1993.

SANTOS, R. B. dos. Movimentos sociais urbanos. São Paulo: Ed. UNESP, 2008.

SANTOS, M. Espaço \& método. 3. ed. São Paulo: Nobel, 1992. (Coleção Espaços). Por uma economia política da cidade. São Paulo: Edusp, 1994.

. A dimensão histórico-temporal e a noção de totalidade em geografia. In:

SANTOS, M. Técnica, espaço, tempo: globalização e meio técnico-científico-informacional. São Paulo: Hucitec, 1997. p. 114-118.

Território e sociedade: entrevista com Milton Santos. São Paulo: Fundação Perseu Abramo, 2000. 
. Por uma outra globalização do pensamento único à consciência universal. 5. ed.

Rio de Janeiro: Record, 2001.

. A natureza do espaço. São Paulo: Edusp, 2002.

2002.

O País distorcido: o Brasil, a globalização e a cidadania. São Paulo: Publifolha,

Por uma geografia nova: da crítica da geografia a uma geografia Crítica. 6. ed.

São Paulo: EdUSP, 2004.

. O espaço do cidadão. 7. ed. São Paulo: EdUSP, 2007.

SANTOS, M.; SILVEIRA, M. L. O Brasil: Território e sociedade no início do século XXI. Rio de Janeiro: Record, 2001.

SANTOS, M.; SOUZA, M. A.; SILVEIRA, M. L. Território: globalização e fragmentação. 3. ed. São Paulo: Hucitec/Anpur, 1996.

SAQUET, M. Proposições para estudos territoriais. Geographia, Rio de Janeiro, n. 15, p. 71-85, 2006.

Por uma Abordagem Territorial. In: SAQUET, M. A.; SPOSITO, E. S. (Org.).

Territórios e Territorialidades: teorias, processos e conflitos. São Paulo: Expressão Popular, 2009.

SÃO PAULO. Secretaria Estadual de Assistência e Desenvolvimento Social. São Paulo Capacita CRAS: Marcos Legais. São Paulo, 2009. v. 1.

SILVEIRA, M. L. Território usado: dinâmicas de Especialização, dinâmicas de diversidade. Ciência Geográfica, Bauru, v. 15, n. 1, jan./dez. 2011.

SMITH, N. Desenvolvimento desigual: natureza, capital e a produção do espaço. Rio de Janeiro: Bertrand Brasil, 1998.

SPOSATI, A. O primeiro ano do Sistema Único de Assistência Social. Revista Serviço Social e Sociedade, São Paulo, n. 87, p. 96-122, 2006.

Territorialização e desafios à capacidade de participação política. Gestão pública inclusiva: o caso da assistência social no Brasil. In: CONGRESO INTERNACIONAL DEL CLAD SOBRE LA REFORMA DEL ESTADO Y DE LA ADMINISTRACIÓN PÚBLICA, 13., Buenos Aires, 2008.

YAZBEK, M. C. As ambiguidades da assistência social brasileira após dez anos de LOAS. Revista Serviço Social \& Sociedade, São Paulo, ano 25, n. 77, mar. 2004. 